\title{
Financial constraints and the failure of innovation projects
}

\author{
José García-Quevedo (\$), Agustí Segarra (\$) and Mercedes Teruel (\$)
}

\begin{abstract}
:
Although many innovation projects are abandoned before completion, the empirical evidence has focused on the determinants of innovation, while failed projects have received little attention. This paper analyses the role of financial obstacles on the likelihood of abandoning an innovation project by potentially innovative Spanish firms for the period 2005-2013. Our analysis differentiates between the impacts of internal and external barriers on the probability of abandoning a project, and we examine whether these differ depending on the stage of the innovation process. Controlling for potential endogeneity, we use a bivariate probit model to take into account the simultaneity of financial constraints and the decision to abandon an innovation project. Our results show that it is during the conception stage that financial constraints have their greatest effect on the probability of abandoning an innovation project. In addition, the financial sources are not neutral across the innovation project lifecycle. During the design phase, Spanish firms are more sensitive to internal financial sources while, during the execution stage, they are more sensitive to external sources.
\end{abstract}

Keywords: barriers to innovation, failure of innovation projects, financial constraints JEL Classifications: O31, D21

Contact: agusti.segarra@urv.cat

(\$) Research Group of Industry and Territory, Department of Economics and CREIP Universitat Rovira i Virgili

Av. Universitat, 1; 43204 - Reus (Spain)

(\$) Department of Economics and Barcelona Institute of Economics (IEB) University of Barcelona

Av. Diagonal 690; 08034 - Barcelona (Spain) 


\section{Introduction}

Innovation projects, particularly radical ones, frequently fail because of their intrinsic characteristics of uncertainty and information asymmetries. Furthermore, theoretical and empirical approaches have stressed the existence of financial constraints in the innovative activities of firms (Hölzl and Janger, 2014; Segarra et al., 2008) and, specifically, in the development of product and process innovations (D'Este et al., 2012; Mancusi and Vezzulli, 2014; Amara et al., 2016).

In recent years, the increasing empirical literature on financial restrictions on R\&D investments and innovation performance at firm level has made substantial advances. This literature has examined several key themes relating to financial constraints. Some papers show that different profiles of firms result in financial constraints having different impacts on innovation activity (Mohnen et al, 2008; Savignac, 2008; Canepa and Stoneman, 2008; Tiwari et al, 2008). Other papers point out the role of firms and sectorial characteristics (Efthyvoulou and Vahter, 2016), but very few papers, other than (Mohnen et al., 2008; García-Vega and López), have focused specifically on the abandonment of innovation projects. To the best our knowledge, none of literature takes into account the different phases of innovation projects so it is unknown whether the effect of financial constraints on an innovation project differs depending on the phase of the project.

Our paper aims to reduce this gap in the literature-our main objective is to analyse how financial constraints change the probability of abandoning an innovation project in its different phases. In addition, we distinguish between internal and external constraints. This paper offers evidence to partially reconcile the seemingly contradictory arguments regarding the role of the limitations of financial resources as inhibitors or facilitators of innovation activities (Hoegla et al., 2008). We consider that, throughout the different phases of the project, an innovative firm offers information to its managers and stakeholders regarding the risks assumed in the project and a firm's capacity to ultimately innovate. Managers will evaluate the financial and technological viability of each innovation project. The decision to abandon an innovation project is not a negative decision "per se". However, when the decision to stop is due to the existence of financial constraints, this decision becomes crucial.

Hence, this paper analyses the role of financial constraints on the likelihood of Spanish firms abandoning an innovation project during the period 2005-2013. We use two direct indicators of financial constraints, distinguishing between internal and external financial obstacles that are related to the access to funds for financing the investments in $R \& D$ and innovation activities. Our panel data is drawn from the Technological Innovation Panel (PITEC) and comprises an extensive sample of Spanish firms from Community Innovation Survey (CIS). Our dataset provides a large variety of indicators on firm's innovative performance for a sample of Spanish firms over a nine-year period. However, it does not include information on innovation projects and this is a common drawback of innovation surveys. Hence, we lack detailed information about each project, the number of innovation projects that a firm 
is conducting, and which of them are abandoned. Nevertheless, we know whether a firm abandons at least one innovation project, and in which stage. Hence, we are able to analyse whether the firms experience financial restrictions and the impact of these on the decision to abandon innovative projects.

Although the access to financial sources may restrict the capacity of potentially innovative firms to carry out innovation projects, the empirical literature is not as conclusive as one might expect regarding the existence of significant financial constraints. ${ }^{1}$ We contribute to this stream of empirical literature by differentiating between the impacts of internal and external financial barriers on the probability of abandoning a project. We consider also that these two financial sources may have different impacts at different stages of the innovation project. Hence, we examine the impacts of internal and external financial constraints on the probability of abandoning the innovation project prematurely, or once it has started.

We apply a recursive biprobit model to take into account financial constraints simultaneously with the decision to abandon an innovation project and controlling for potential endogeneity. Our results show that financial constraints are directly correlated with the probability of abandoning an innovation. In addition, internal financial constraints have a greater effect on an innovation project's failure during the conception stage, while external constraints have a greater effect in the execution stage.

The remainder of the article is structured as follows. Section 2 analyses the literature related to financial constraints to innovation and presents our main hypotheses. Section 3 describes the database and main statistics. The following section presents the econometric methodology. Section 5 shows our main empirical results. Finally, Section 6 presents the main conclusions.

\section{Innovation projects and financial constraints}

The nature of the innovation projects is characterised by the generation and implementation of new knowledge. Consequently, two groups of market failures affect the development of the innovation projects. On the one hand, some failures are due to the nature of knowledge (Arrow, 1962) such as appropriability, high sunk costs, high risk with a skewed distribution of outcomes, and spillovers. Firms have incentives to generate innovations, but they have to evaluate the risk they assume since more novel projects are associated with a higher failure probability (D’Este et al., 2016). On the other hand, there are systemic failures of innovation systems (Nelson and Winter, 1982) such as lack of confidence in cooperating in R\&D, the agents involved lacking the scale to cope with the challenges of innovation, and there being

\footnotetext{
${ }^{1}$ Some articles have strongly criticized the positive correlation between R\&D and internal financial sources, in particular cash-flow, since it may also reflect that innovative firms anticipate high future profits that, in consequence, lead them to invest strongly (Savignac, 2008). The presence of financial constraints for innovative firms is frequently investigated via the sensitivity of R\&D investment to financial factors (Himmelberg and Petersen, 1994; Harhoff, 1998; Mulkay et al., 2001; Tiwari et al., 2008). In recent years, a new line of research has focused on the analysis of the impact of financial constraints on R\&D risk projects.
} 
few linkages between the agents involved in the innovation process. In consequence, innovative firms find more obstacles to financing their innovation activities in freely competitive financial markets (Hall and Lerner, 2010) and under-invest in R\&D activities (Hall, 2002).

In essence, innovative firms encounter financial obstacles to investing in innovative activities through the presence of externalities, problems of informational asymmetries and problems of appropriability with the return on R\&D investment (Mina et al., 2013). Consequently, innovative firms experience high costs for $R \& D$ investments and induce underinvestment in innovation activities. These problems can generate a gap between external and internal costs that leads to R\&D underinvestment or liquidity constraints. ${ }^{2}$

Although the literature has paid less attention to the conceptualization of failure of innovation projects, recent empirical evidence may suggest that facing financial barriers increases the likelihood of failure of innovation projects (Hall, 2002; Canepa and Stoneman, 2008; Savignac, 2008; Blanchard et al., 2012). Consequently, some innovation projects may not be started, must be delayed, or are abandoned because of a lack of access to financial resources. Using the Dutch CIS survey, Mohnen et al. (2008) analyse the impact of financial constraints on the hampering of innovation. According to their results, financial constraints "have a significant and positive impact on the three probabilities of prematurely stopping, seriously slowing down and not starting a project, but not on that of abandoning a project".

More recently, García-Vega and Lopez (2010) analyse a sample of more than 8,300 innovative Spanish firms for the period 2005-2007. Their results show the importance of the lack of funds on the probability of abandoning innovation projects. In particular, large firms are much more affected, since they invest in innovation projects that involve a larger amount of funds. Based on these analyses, we assume that failures of innovation projects are positively correlated with the presence of financial constraints.

Despite the previous evidence, the literature has not analysed the interaction between the type of financial source and the impact on the failure of the innovation project over its different development stages. We consider that this is relevant because of the nature of innovation projects and because the existence of financial constraints affects managers' decisions when allocating limited financial resources across their project portfolio. The financial strategy of a firm may respond to managerial perception of the sources of firm competitiveness. Hence, managers who aim to develop innovation projects have to understand when to invest, how much to invest and also the type of financial source. The latter is particularly relevant since the nature of financial sources, external or internal, is not neutral to the development stage of innovation projects (Fazzari et al., 1988).

\footnotetext{
2 The empirical analysis remarks how financial barriers restrict the capacity of innovative firms to carry out innovation projects ("hampering barriers") and how financial constraints reduce the capacity of potentially innovative firms to become innovative firms (“deterring barriers"). Following D'Este et al. (2012), some barriers may deter some firms from engaging in innovation activities, and other barriers may affect firms which are engaged in innovation and may delay their initial plan.
} 
Concerning the stage of the innovation project, the level of risk during the initial stages is significantly higher than once the innovation project has started. This will affect any financial decisions of the different agents involved in the investment (see Carreira and Silva, 2010).

In general, the expected viability of the project will depend on the proximity to the market in temporal and technological terms. External investors may be more prone to investing in innovation projects where the technological viability and market opportunities are clear, and they will be sensitive to riskier projects. However, some investors may prefer low risk and short-term gains, while others may pursue high risk and long-run innovation targets (Mazzucato, 2013). Some external investors, such as venture capitalists, selectively participate in high risk projects. Indeed, venture capital may be critical at the initial stages by providing capital, and also by initiating screening and monitoring processes (Jain and Kini, 2000).

Due to the risky nature of the R\&D activity, and as evidenced by Hall (1992), managers may have to finance their projects with internal funds (Chiao, 2002; Bougheas et al., 2003). Hence, if external financial sources are lacking, managers may compensate for this during the initial phases by investing internal funds. In that event, the innovation projects in their initial phases will be more sensitive to internal financial constraints, in particular among young innovative firms. Innovative firms may prefer internal financial sources to finance innovation activities given their lower cost, fewer constraints and lower risk. Generally speaking, internal financial sources reduce the debt pressure of corporations.

Myers and Majlufs (1984) Pecking Order Theory of financing provides a potential explanation. Their model highlights the information asymmetries between managers and external investors when evaluating firms' investment projects. These information asymmetries are larger during the concept phase of the projects, causing a higher cost of external funds (debt and equity financing) than internal financing (cash-flow and retained income). Once the innovation project starts, the information asymmetries decrease and financial external investors are more able to evaluate the viability of the innovation projects and, consequently, they will be more prone to invest. Following the Pecking Order Theory, innovative firms sort the financial sources of $R \& D$ investment from internal to external sources according to their cost. Initially, innovation projects will be supported by internal sources and later the share of external sources increases. However, the internal funds invested by a firm will be positively associated with the innovative opportunities of the project (Myers and Majluf, 1984; Kamien and Schwartz, 1978).

The above arguments show, as the literature emphasizes (Fazzari et al., 1988; Hall and Lerner, 2010; Hottenrott and Peters, 2012), that internal and external funds are not perfect substitutes to finance innovation projects. The differences between both sources of funds are likely to be greater depending on the phase of the innovation projects. Firms prefer to use internal funds to finance innovation projects, and it is very likely that they use these funds to finance projects that are in the design and conception stage. During the conception stage, 
managers prefer to use internal funds because it is more difficult to find external investors and, additionally, the financial costs are higher. In this stage, the required funding is probably less than that needed in the subsequent stages of the innovation project, and the risk is very high, making more difficult to obtain external funds. Therefore, encountering internal financial constraints may result in the abandoning of innovation projects. This may happen also to highly innovative firms. As Hottenrott and Peters (2012) show, firms with high innovative capability and low levels of internal funds are more likely to be constrained than firms with greater liquidity.

Internal resources are commonly not enough to finance innovation projects, and firms may thus need complementary external funds for development. In addition, firms often need to access external funds several times in order to finance ongoing innovation (Kerr and Nanda, 2015). It is very likely that innovation projects need external funding more frequently in their execution than in their conception stage. In the former, the firm's own resources may not be enough to finance the project, while the information asymmetries have decreased, making access to external finance easier than in the conception stage. Nevertheless, the inherent characteristics of innovation activities may continue to make external funding difficult to obtain, and the cost of this external capital may be too high, resulting in innovation projects being abandoned during the execution stage.

In summary, across the lifecycle of the innovation projects there is a trade-off between informational asymmetries and financial sources which affects the decision to abandon an innovation project. Therefore, we consider that financial sources may not be neutral across the stage of development of innovation projects and we propose the following hypotheses:

H1: Internal financial constraints increase the probability of abandoning innovative projects during the conception stage.

$\mathrm{H} 2$ : External financial constraints increase the probability of abandoning innovative projects during the execution stage.

From these two hypotheses, it is expected that, on the one hand, internal financial constraints have a greater impact on the abandonment of an innovation project at the conception stage than at the execution one. On the other hand, the impact of external financial constraints is likely to be greater during the execution stage than in the conception phase of the innovation project.

\section{Database}

\subsection{The database}

The data used for the analysis are drawn from the Spanish Technological Innovation Panel (PITEC), which is carried out yearly by the Spanish National Statistics Institute (INE) in collaboration with the Spanish Science and Technology Foundation (FECYT) and the 
Foundation for Technological Innovation (COTEC). PITEC is a panel dataset based on the Community Innovation Survey (CIS) framework, enabling direct comparisons with results of previous literature on similar data sets. The main advantage of CIS data is that it contains detailed information on innovation behaviour at firm level. ${ }^{3}$

Our dataset provides exhaustive information for a sample of Spanish firms over an elevenyear period. The sample used in the econometric estimations includes potentially innovative firms in the manufacturing and service sectors. Furthermore, since 2010 PITEC provides the setup year, we have access to the firm's age. PITEC is representative of innovative firms in Spain. It includes nearly all the firms with 200 or more employees, most of the firms with intramural $R \& D$ expenditures or external $R \& D$, and even a representative sample of firms with fewer than 200 employees and without innovation expenditures. By offering panel data which covers the period 2005-2013, PITEC overcomes the CIS drawback of only providing cross-sectional data. Hence, PITEC is the best database for observing the innovation activities of Spanish firms over time and has been frequently used to carry out empirical analysis on R\&D and innovation (see, among many others, Barge-Gil, 2010; Belderbos et al., 2014; Busom et al., 2014).

Finally, the PITEC survey provides information about the stages of innovation projects which is very useful in examining the effects of financial constraints. Specifically, it offers information concerning the stage at which a firm abandons an innovation project. Hence, we can observe the sensitivity to each financial source constraint during the conception stage, and once the project has commenced.

However, CIS and PITEC data have several constraints. First, since CIS tends to have an overrepresentation of firms that carry out innovative activities, 'potential innovators' might be underrepresented. Second, our indicators for lack of finance have a qualitative dimension and are proxies of the existence of financial constraints. ${ }^{4}$ Third, it does not offer information on firms' balance sheets, which would allow us to assess the impact of internal or external finance on the behaviour of $R \& D$ investment. Finally, financial constraints and the innovation pattern at firm level are dynamic and time may be a relevant variable.

The procedure for filtering our sample is the following. First, we restrict our sample to firms with at least 8 or 9 observations, hence, those that appear in 2005 or 2006 and remain active until 2013. Second, we drop firms that have undergone a process of mergers. Third, we select firms that are potentially innovators since they will perceive financial constraints more directly. Following Savignac (2008), D’Este et al. (2012) and Blanchard et al. (2012), we exclude firms that do not have an intention of innovating since they will not perceive any

\footnotetext{
3 CIS include as innovation activities the acquisition of machinery, equipment, software, and licenses; engineering and development work, training, marketing and $\mathrm{R} \& \mathrm{D}$ when they are specifically undertaken to develop and/or implement a product or process innovation.

${ }^{4}$ However, recent studies (Hadlock and Pierce, 2010) have cast doubts on the validity of the Kaplan and Zingales's (1997) index of constraints to proxy for financial constraints.
} 
financial constraint in relation to $R \& D$ activities. Hence, we do not take into account firms that do not innovate and do not declare that they face any type of barrier. ${ }^{5}$ After empirical treatment, our sample contains 4,600 firms. Among these potentially innovative firms, 4,298 firms innovated successfully between 2005 and 2013, while the remaining 302 firms did not actually innovate, but felt they had encountered barriers to them engaging in innovation activities.

\subsection{Variables}

First, our dependent variables capture whether a firm abandons an innovation project, distinguishing between the initial phase of the project and the execution stage. $A B \_c o n c \_p r o j$ indicates those firms that abandon a project, while $A B \_c o n c$ and $A B \_$proc indicate when the project is abandoned: during the conception stage $\left(A B \_c o n c\right)$, or once the innovation project had started $\left(A B \_p r o j\right){ }^{6}$ The questionnaire asks whether: i) during the last three years, any of the innovation activities were abandoned during the initial period; ii) during the last three years, any of the innovation activities or projects were abandoned once the activity or project was initiated.

Our main explanatory set of explanatory variables is related to the perception of financial constraints. FCinternal captures the lack of funds within a firm or group; FCexternal captures the lack of funds from sources outside a firm, and FC captures the lack of funds regardless of the source. The survey asks how important, during the last three years, were the funds in preventing or in hampering innovation activities. These three dummy variables are equal to 1 in the case that the firm states it perceives a high level of financial constraint and nil when the degree is medium, low or null. ${ }^{7}$

The control variables are the following. In Age measures the firm age (in natural logs) as the difference between the period of observation and the year of creation. InSize measures the number of employees (in natural $\operatorname{logs}$ ). $R D$ is a dummy variable that captures whether the

\footnotetext{
${ }^{5}$ In other words, potentially innovative firms are those firms who engaged in innovation activities or did not do so due to one or more obstacles. As D'Este et al. (2012) point out, this exclusion is based on the rationale that these firms are unlikely to have any aspiration to innovate.

${ }^{6}$ The Spanish CIS questionnaire considers other alternatives related to a serious delay in the innovation project, but it only appeared in 2004 .

${ }^{7}$ There are certain limitations when measuring financial constraints and attempting to find the proper indicators for carrying out empirical research at the firm level (Czarnitzki and Hottenrott, 2010; Salies, 2010). In that sense, there is wide-ranging discussion in the literature regarding the determinants of the financial constraints. Recently, Hadlock and Pierce (2010) analyse different financial measures to explain financial constraints. Their results suggest that financial constraints may be reasonably better approximated based on firm age and firm size than with respect to other more complex financial indexes such as Kaplan and Zingales (1997) or Whited and Wu (2006). Their results deal with the fact that young and small firms suffer from "liability of newness" due to the fact that entrants who are characterised by small sizes have a lower survival likelihood. This results in them experiencing larger financial market failures. In this paper, we adopt a direct approach based on the firms' own assessments from the information provided in the CIS in the same way as the remaining potential barriers (knowledge, market) used in the empirical analysis. This is the only information regarding financial constraints provided by PITEC. Obtaining additional indicators, such as cash flow or dividends, would require merging PITEC with other databases. However, this is not possible due to PITEC's anonymity requirements.
} 
firm invests in R\&D or 0 otherwise. Group is a dummy variable that takes a value equal to 1 if the firm belongs to a group. Know and Market are dummy variables that indicate whether the firm perceives a medium or high level of barriers related to knowledge or market factors. InPatents is the number of patents generated by a firm a year plus 1 (in natural logs). ${ }^{8}$ Coop is a dummy variable controlling whether a firm cooperates with other agents. InternatMarket takes a value equal to 1 in the case that the firm participates in international markets. InRDintensity is the R\&D investment per employee in thousands of Euros (in natural logs). InKL sector indicates the real stock capital per worker intensity (in natural logs). The source is the EUKLEMS database and we have information up to 2009. Between 2009 and 2012, we assume a growth rate of the stock of capital intensity equal to the last year (2008-2009). FinLocReg, FinState, and FinEur are dummy variables equal to 1 if the firm receives a financial support from a local/regional government, the State, or Europe. Finally, we also include industry and time dummies to control differences in the probability of abandoning a project and of experiencing financial constraints across sectors and over time.

\subsection{Descriptive analysis}

Table 1 presents the distribution of observations according to whether firms abandon a project or not and according to whether they perceive financial constraints. We observe that $23.57 \%$ of potentially innovative firms state that they abandon an innovation project during the concept and/or project stage. First, we must highlight that the percentage of firms perceiving financial constraints is larger among the group of firms that abandon an innovation project than those that do not abandon one. Second, differences appear when distinguishing according to the stage: $57.03 \%$ of firms that abandon the project once the project has started state they do not perceive any financial constraint, while this percentage diminishes to $48.57 \%$ for firms that abandon the project during the conception stage. Third, when comparing firms according the stage that abandon, the percentage of firms abandoning once the project has started and that perceive external financial barriers is significantly lower than the percentage of firms that abandon during the conception stage. Hence, this preliminary descriptive would indicate a positive association between the perception of financial barriers and the probability of abandoning a project, in particular during the conception stage.

\section{---- Insert Table 1 ----}

Additionally, following Canepa and Stoneman (2008), we estimate the Pearson $\chi^{2}$ and the conduct the likelihood-ratio (LR) to test whether the rows and columns in the two-way tables

\footnotetext{
8 This variable introduces the concept of innovative capability. In line with previous literature (Hottenrott and Peters, 2012), there may be an interaction between a firm's innovative capability and the sensitiveness to perceiving financial barriers. A recurrent drawback in these empirical studies is that information about the number of projects that a firm has is unavailable. We correct for this by introducing the number of patents held by a firm. Our results show that those firms with more patents have a greater probability of abandoning R\&D projects. The impact of the number of patents is particularly high for firms in the low-tech manufacturing firms and non-KIS services.
} 
are independent. The test statistics suggest that there are differences in the percentage of firms perceiving financial constraints according to whether or not they abandon an innovation project.

----- Insert Table 2 -----

Table 2 provides the overall means of the main variables used in our econometric analysis and compares four groups of firms: (i) firms that do not abandon a project; (ii) firms that abandon a project during any stage; (iii) firms that abandon a project during the conception stage; and (iv) firms that abandon a project once the project has started.

First, it is interesting to note that firms that abandon a project are, on average, older and larger than those that do not abandon a project. $R D$ and $R D$ intensity are significantly higher for those firms that abandon a project. In particular, firms that abandon during the execution stage demonstrate a higher average $R \& D$ intensity. Second, a large percentage of firms state that they perceive some type of knowledge or market barriers. However, this percentage increases to over $90 \%$ for firms that abandon a project. Third, significant differences appear when considering the proportion of firms belonging to a group, cooperating with other firms, and competing in international markets. In these categories, a larger proportion of firms abandon a project than do not. Fourth, the sectoral capital intensity per worker is larger for firms that do not abandon a project. Fifth, firms that do not abandon receive less public support to finance innovation; among those that abandon, those that do so during the conception stage receive more public funding. Finally, regarding patent numbers, firms that abandon an innovation project have a larger mean number of patents.

----- Insert Table 3 -----

Table 3 shows the correlations between our explanatory variables. All the correlations show a low level of significance.

\section{Econometric methodology}

Our aim is to examine the determinants of Spanish firms abandoning innovation projects between 2005 and 2013. In line with previous scholars, we consider that financial obstacles affect the probability of deterring innovation projects. In other words, a firm's financial constraints significantly affect the likelihood that it abandons innovative activities.

$$
\begin{array}{ll}
\text { ABANDON }_{i t}=X^{\prime}{ }_{i, t} \beta_{1}+\gamma_{11} R \& \text { Dintensity }_{i, t-1}+\gamma_{12} F C_{i, t}+\varepsilon_{1 i, t} & \text { Eq. [1] } \\
F C_{i t}=X^{\prime}{ }_{i, t} \beta_{2}+Y^{\prime}{ }_{i, t-1} \gamma_{21}+\varepsilon_{2 i, t} & \text { Eq. [2] }
\end{array}
$$

However, there may be an endogeneity problem, since the financial constraints and the abandoning of an innovation project may be affected by common elements of unobservable heterogeneity (for instance the quality of the project). As in Savignac (2008) and Blanchard 
et al. (2012), we employ a biprobit model composed of two equations. ${ }^{9}$ Our main equation of interest (Equation [1]) estimates the determinants of abandoning an innovation project and our main explanatory variable is the perception of financial constraints. Simultaneously, we estimate the probability that a potentially innovative firm perceives financial constraints (Equation [2]). Both equations include a set of control variables (X). Although there is no need for each equation to have its own dependent variables, we have included some different explanatory variables which may have a direct impact on both dependent variables (see Greene (2003, Chapter 21). See Subsection 3.2 for details of the dependent and explanatory variables.

We should also mention that CIS datasets present a potential endogeneity. Firms may be more likely to indicate 'some' lack of finance the more innovation projects they conduct (and thus the greater the amount they invest in $\mathrm{R} \& \mathrm{D}$ ). To resolve this issue, estimation methods usually use instrumental variables (Czarnitzki and Hottenrott, 2009). As in Efthyvoulou and Vahter (2016), we estimate a dynamic equation of the determinants of the R\&D intensity depending on the firm age, firm size, group, $R \& D$, cooperation, sectoral $R \& D$ intensity, sectoral and time dummies. With this procedure, the predicted value of the R\&D intensity and the estimated error terms are introduced in Equation [1] and in Equation [2].

Finally, following Rabe-Hesketh and Skrondal (2013), we apply a refined version of Wooldridge's (2005) model to estimate all the equations. Hence, we add the lagged dependent variable and its initial value, and the within-means of the explanatory variables based on all periods (excluding the first). The time-average of the explanatory variables allow us control for a correlation between the individual specific impacts and the time-varying variables. ${ }^{10}$

\section{Results}

Table 4 presents the analysis of the impact of financial constraints and other control variables on the probability of abandoning a project.

With respect to the determinants affecting the probability of encountering financial constraints, the main results are the following. First, there is a clear persistence of financial constraints since the lagged value of the dependent variable shows a positive and significant impact. Also, its initial value shows a positive and significant impact. Hence, firms are

\footnotetext{
9 According to Savignac (2008), the probability of deterring innovative activities and the presence of financial restrictions must be estimated simultaneously, since there is a strong endogeneity between innovative activities and financial constraints. In other words, financial constraints significantly reduce the likelihood that firms carry out innovative activities and, conversely, innovative firms enjoy a higher probability of generating ex-ante internal resources in order to reduce financial restrictions in investment decisions. The bivariate probit model takes into account the correlations between the likelihood of failure of an innovation project and its facing financial barriers. The bivariate probit estimation, where we assume normality of the error terms, provides a correlation parameter that yields information about the co-variation of the error terms of the two estimations. ${ }_{10}$ We have also investigated the existence of a sample selection bias due to the estimation of only the potentially innovative firms. Controlling for the condition a firm may be potentially innovative, we included the Mill's ratio and this was only significant in the equation of the perception of internal financial barriers. We are grateful to an anonymous referee for this suggestion.
} 
persistently feeling financial constraints controlling for other variables. Second, some of our control variables, such as firm age, firm size, the R\&D activity and the sectoral capital intensity, do not exhibit a significant impact on the probability of perceiving financial restrictions.

Controlling for the potential endogeneity, our results do not confirm previous evidence. For instance, Savignac (2008) finds that the probability of financing constraints decreases with firm size and depends on the firms' ex-ante financing structure, while Blanchard et al. (2012) assert that firms investing in $\mathrm{R} \& \mathrm{D}$ will be more likely to face obstacles. However, the timeaverage of belonging to a group diminishes the probability of perceiving external financial constraints. Our results are consistent with Tiwari et al. (2008) and Galia et al. (2012) whose evidence indicates that firms may obtain financial support for their R\&D activities more easily when they belong inside a group of firms. If we turn to the public financial variables, one interesting finding is that the sign of the access to State public funds is the opposite to that of the corresponding time-averaged variable. In particular, firms that have access to State public funds show a lower probability of perceiving external financial constraints. However, the time-average values of the access to State funds shows a positive and significant impact on the probability of perceiving financial constraints regardless of the financial source. The interpretation of this finding is that the access to previous State public funds decreases the perception of financial barriers; however, in the long-run, firms which are accessing to State public funds have a larger probability to perceive financial constraints. Finally, the timeaverage of the access to the European funds also shows a positive impact on the probability of perceiving financial constraints.

---- Insert Table 4 ----

In regard to the determinants affecting the probability of abandoning a project, our findings are the following. Table 4 presents the estimation of the determinants of abandoning an innovation project (Columns (1 to (3)), secondly the probability of abandoning a project during the conception stage (Columns (4) to (6)), and finally the probability of abandoning once the project has started (Columns (7) to (9)). Each equation will consider our three types of financial constraints, FC, FCinternal and FCexternal.

First, in line with Mohnen et al. (2008), financial constraints in general increase the probability of abandoning a project. However, distinguishing the stage of abandonment seems important since financial constraints are only significant when abandoning the project during the conception stage, whereas once a project has started, only external financial constraints have a positive significant impact on the abandonment probability. A possible explanation may be related to the existence of high sunk costs for R\&D activities. Once a firm carries out R\&D activities, other factors may be more important in abandoning a project. Finally, it seems that external financial restrictions have a much greater impact on the probability of abandoning an $\mathrm{R} \& \mathrm{D}$ project. 
Table 5 presents information on the marginal probability of perceiving financial constraints and significance testing for this variable in our equation. The results confirm that we should distinguish between innovation projects abandoned during the conception stage and the execution stage. First, while internal and external financial constraints show a significant impact on the probability of abandoning an innovation project during the conception stage, we observe that perceiving internal financial constraints increase the probability by $1.690 \%$, while perceiving external financial constraints will increase the probability of abandoning an innovation project during the conception stage by $1.452 \%$. Hence, we confirm that both financial sources are important, and that the impact is slightly larger for internal resources.

Second, firms that have initiated an innovation project and perceive internal financial constraints will see an increased probability of abandoning some innovation project of $0.216 \%$; the corresponding probability increase for firms perceiving external financial constraints being $1.084 \%$.

---- Insert Table 5 ----

Firms perceiving external financial constraints will be more likely to abandon their innovation projects in both stages. However, internal financial constraints are more important during the conception stage. All in all, we confirm our hypothesis that the sources of financial constraints are sensitive to the stage of development of the innovation project. On the one hand, the internal financial sources seem to be more important during the period where the innovation projects are further from the market and where the uncertainty is higher (Hypothesis (1) would be confirmed). On the other hand, the lack of external funds will have an effect during both stages (Hypothesis (2) would be confirmed, but also is significant for the conception stage).

Second, our results show that those firms that abandon an innovation project the previous year are more likely to abandon an innovation project on the future. Hence, a certain persistence of abandoning a project appears among potentially innovative firms.

Third, other barriers related to knowledge and market, they increase the probability of abandoning a project. However, the results are only significant for firms that state the abandonment of a project during the conception stage. This result may indicate that, during the initial period, the probability of abandonment not only depends on financial constraints but also on other barriers, where viability and technical difficulties may also be important.

Fourth, with respect to firm age we observe that the impact is not significant. This result may be due to the fact that young firms assume more risks through lack of experience, while older firms will have more experience but also a larger number of R\&D projects. Hence, firm age may not show a clear pattern. 
Fifth, one interesting finding is that the sign of the lagged firm size is opposite to the corresponding time-averaged variable. The interpretation of this finding is that increasing the number of employees during the previous year may increase the probability of abandoning a project; however, in the long run, firms with larger firm size have a lower probability of abandoning an innovation project. According with Canepa and Stoneman (2008, p. 720), the positive relationship between firm size and the probability of abandoning an innovation project "may reflect the fact that larger firms on average have higher levels of R\&D spending and broader production programmes, and thus may have a greater likelihood of engaging in risky projects; as a result they may be more likely to terminate projects".

However, the fact that average value of firm size shows a negative impact may also be related to the potentially greater number of tools available to large firms. The complex and uncertain nature of the innovation projects results in a need to screen them and there are many techniques to evaluate and choose project portfolios (Archer and Ghasemzadeh, 1999). Because of the complexity, some firms may not be able to correctly manage the risk and uncertainty. Hence, small firms may show a larger propensity to fail in innovation projects because they do not have access to these tools and, consequently, they have less capacity to screen those projects. For instance Love et al. (2005) point out for the case of the IT projects that "the lack of risk identification and management is a major contributing factor to project failure-especially for SMEs who "frequently suffer from limited IT competencies and poor understanding of IT capabilities and the risks involved. Finally, the higher failure propensity of small firms may be explained by the lower capacity of small and young firms to appropriate the returns of the investment in innovation projects. Our results may show both realities: larger firms have a larger portfolio of innovation projects, but also larger resources to be devoted to assess and screen innovation projects.

Furthermore, the lagged number of patents shows a non-significant impact. However, the time-averaged value shows a significant positive impact, with the exception of the abandonment once the project has started. Hence, those firms that show a larger capacity to formally protect their knowledge have a greater propensity to abandon a project. This suggests that these firms have a larger number of projects and, in consequence, the probability of having abandoned at least one project is also larger.

With respect to $\mathrm{R} \& \mathrm{D}$ cooperation, we also observe an opposite sign between the lagged variable and the time-average value. Our results indicate that the lagged cooperation in $R \& D$ shows a positive and significant impact on the likelihood of abandoning a project. However, the coefficient of R\&D cooperation is larger when we estimate the probability of abandoning a project during the conception stage, rather than once it has started. This result must be interpreted carefully since this variable may indicate that firms that start risky projects will cooperate more frequently. Evidence along these lines can be found in Lhuillery and Pfister (2009) who observe that firms which are collaborating are more likely to delay or stop an innovation project due to difficulties encountered in their R\&D partnerships. Furthermore, 
their results show that firms collaborating with their suppliers also face a higher risk of cooperation failures.

However, the fact that the time-averaged value shows a significant negative impact on the probability of abandoning may point out that those firms that constantly cooperate are able to reduce the probability of abandoning. The reason may be that firms which are able to establish enduring $\mathrm{R} \& \mathrm{D}$ cooperation with other partners may mitigate risks and increase their capacity to develop innovation projects.

With reference to international competition, the coefficient shows a positive impact on the probability of abandonment. One possible explanation of this result is that international competition obliges firms to be more competitive by investing in $\mathrm{R} \& \mathrm{D}$ projects. While in the long-run R\&D projects may increase price-cost margins, in the short-run, firms have to survive the concurrent international competition and, consequently, they may be more prone to abandon an innovation project. Another possible explanation is that internationalized firms may be better able to screen the viability of innovation projects and hence will be more prone to abandoning. However, the impact is not significant when we distinguish by stage and, furthermore, its time-average value does not show a significant impact. Hence, this may indicate that this negative impact would only have an effect in the short-run.

Finally, the lagged investment in R\&D has a positive and significant impact on the likelihood of abandoning a project only once the project has started, while its time-average shows a positive impact regardless of the stage. Hence, those firms that show a larger average R\&D investment during the period show a larger probability of abandoning a project regardless of the project. Hence, our results may be related to the fact that those firms with higher capacity to constantly invest in $\mathrm{R} \& \mathrm{D}$ activities may have a greater capacity to carry out new and different projects during the conception stage and, consequently, the probability that they will abandon any given project will also increase.

\section{Robustness checks}

As a robustness check, first we analyse the impact of including non-potential innovators in our estimations. Here, we are including firms that they did not declare they innovate and they did not face any innovation obstacle. Table 6 shows the results for our main variables which have been estimated similarly to those in Table 4. We observe that there are no significant differences regarding the impact of the financial constraints on the likelihood of abandoning an innovation project.

---- Insert Table 6 ----

We note that the literature mentions that existing results may be limited by a "survivorship bias" (Mohnen et al., 2008; Landry et al., 2008), since they are not able to "control for firms that did not survive after the failure of an innovation project". Our results may suffer the 
same bias since, although we have all those firms that survived until 2013, some firms were excluded since we were unable to observe them. According to our data, around $4 \%$ of firms are not observed at the end of the period.

---- Insert Table 7 ----

Table 7 shows the results for the whole database including non-potential firms, regardless of the number of periods for which they are observed, and regardless of whether they have disappeared or not at the end of the period. Although it is compulsory for firms to answer the survey, on occasion some have not responded the questionnaire. Consequently, during one or more periods we are unable to track the firm. Our results do not show significant differences in the impact of the financial constraints on both cases. This appears to confirm our results.

Finally, we investigate the incidence of relaxing the level of financial barriers. Recent literature (Coad et al., 2016; García-Quevedo et al., 2016) has considered, as in our main estimation, the existence of barriers to innovation when firms perceive a high degree of innovation obstacles. Nevertheless, other analyses (Canepa and Stoneman, 2008; Hölzl and Janger, 2014) have considered, as an alternative definition, the firms that rank barriers as medium or highly important. Hence, we may wonder whether a different severity of financial constraints may affect the probability of abandoning an innovation project. Hence, we estimate our estimations by considering the impact of firms which declare to perceive a medium or high level of financial barriers.

\section{---- Insert Table 8 ----}

Table 6 shows similar results to our previous estimations (Table 3) and confirm that the perception of medium or high financial barriers has a positive effect on the probability of abandoning an innovation project. The only exception is that external financial constraints do not significantly affect the probability of abandoning a project during the execution, suggesting that it is only the highly important financial obstacles that have a negative impact.

These three robustness checks confirm the existence of a negative impact of the perception of financial constraints on the probability of abandoning a project.

\section{Concluding remarks}

The aim of this paper is to analyse the impacts of financial barriers on the failure of innovation projects. Although the conceptualisation of failures of innovation projects has received less attention in literature and specific evidence on their determinants is scarce, empirical findings tend to point out that facing financial barriers increases the likelihood of failure of innovation projects (Mohnen et al., 2008). Our interest is in contributing to the literature by analysing the differing impacts of internal and external financial barriers on the 
probability of abandonment of an innovation project during the conception stage and during its execution.

Taking into account the specific characteristics of innovation projects and the financial sources, we propose a framework to show that financial restrictions may not be neutral across the lifecycle of innovation projects. This analysis complements the existing literature by disentangling whether different sources of funds may imply a significantly increased probability of abandoning a project, taking into consideration the stage of the project.

To carry out the empirical analyses we use panel data (PITEC) of Spanish firms for the period 2005-2013. This survey provides specific information about the abandonment of innovation projects and whether this occurred in the conception phase or once the project has started. In addition, it provides detailed information at firm level regarding innovation activities which allows us to include a broad range of independent and control variables. In the empirical estimations, we control for potential endogeneity and we use a bivariate probit model to take into account the simultaneity of financial constraints and the decision to abandon an innovation project.

The main results from the econometric estimations regarding the impacts of financial constraints on the abandonment of innovation projects are as follows. First, we confirm the previous literature and show that, in general, financial constraints increase the probability of abandoning an innovation project. However, we show that it is important to distinguish between the different phases of innovation projects and between internal and external financial constraints. Firms perceiving external constraints are more likely to abandon innovation projects both at the conception stage and once the projects have started. Furthermore, internal financial constraints are important only during the conception stage. In addition, our results suggest that the probability of perceiving financial constraints has a high degree of persistence.

The sensitivity of the probability of abandonment to our proxies of financial constraints indicates the necessity to diminish information asymmetries by means of improved definition of firms. The existence of higher financial constraints in innovative firms justifies public intervention (Schneider and Veugelers, 2010). Governments should create new mechanisms to promote the access to external funds for $R \& D$ projects. We must take into account that banks usually do not have tools to properly measure the risk of innovation projects. However, other variables explain the probability of abandoning a project. In line with previous findings (see Hottenrott and Peters, 2012), money is not the only factor that affects abandoning a project; variables such as the innovative capacity of the firm are also crucial.

We must also mention two different limitations. First, our proxies for barriers are of a subjective nature, being based on the personal appreciation of the respondents. However, we focus on the firms that consider barriers to be highly importance and we have, as a robustness check, used as an alternative definition the firms that rank the barrier as being of 
high or medium importance. Second, we ignore the number of projects that are abandoned. Hence, a firm that abandons one innovation project is considered identical to a firm that abandons three different projects. However, variables such as belonging to a group of firms, firm size and firm age may capture a firm's capacity to carry on innovation projects.

Although the available information has not allowed us to examine the precise role of financial market failures on the abandonment of innovation projects, the literature has shown that these failures increase the difficulty of accessing funds for their $\mathrm{R} \& \mathrm{D}$ projects. Hence, governments act to reduce the financial restrictions. Some of these public actions (venture capital funds, loans and public grants) involve the provision of financial instruments and public aid to facilitate access to public resources, while others strengthen structures that facilitate R\&D cooperation and knowledge transfer (technological transfer, R\&D grants cooperation, universities). Public actions have different impacts on industries and firms. For instance, small firms and KIS services tend to benefit more from actions related to the reinforcement of structures, such as the creation of scientific parks, which generate an innovative atmosphere and encourages R\&D.

Finally, we should remark that the abandonment of an innovation project does not necessarily imply a failure. Indeed, a lack of financial resources which negatively affects the probability of carrying out an innovation project may have a positive effect on the likelihood of the firm's future survival by ensuring its financial equilibrium and allowing the choice more efficient projects. However, the failure of innovation projects is a relevant issue when it is a consequence of financial market failures. Furthermore, our results highlight the complexity of the innovation activity. The fact that other innovation obstacles may impact the abandonment of a project during the conception stage tends to reinforce this idea. Hence, our results highlight that not only financial access is crucial to avoid the failure of innovation project, but also the access to technical knowledge and market conditions.

\section{Acknowledgements}

Previous versions of this paper were presented at the $\cdot 35^{\text {th }}$ DRUID Celebration Conference (Barcelona, Spain, 2013); at the EARIE 2013 Conference (Evora, Portugal); at the XVI Encuentro de Economía Aplicada (Granada, Spain, 2013) and at the XREAP 2013 Symposium (Barcelona, Spain). We would like to thank the participants at these meetings for their helpful comments: We are particularly grateful to the two anonymous referees that provide very useful suggestions and comments. Agustí Segarra and Mercedes Teruel thank the financial support of the Ministry of Innovation and Science (project ECO2015-68061-R) and the Consolidated Group of Research 2014-SGR-1395. José García-Quevedo gratefully acknowledges support from the project ECO2015-69107-R (MINECO / FEDER, EU) and from the Government of Catalonia (2014SGR420). Agustí Segarra, José García-Quevedo and Mercedes Teruel acknowledge the support of the Xarxa de Referència en Economia Aplicada. We are grateful to Verònica Gombau for her research support. The usual disclaimers apply.

\section{References}


Amara, N., D'Este, P., Landry, R. and Doloreux, D. (2016): "Impacts of obstacles on innovation patterns in KIBS firms", Journal of Business Research, 69: 4065-4073.

Archer, N.P. and Ghasemzadeh, F. (1999): "An integrated framework for project portfolio selection", International Journal of Project Management, 17(4): 207-216.

Arrow, K.J. (1962): “The Economic Implications of Learning by Doing”, Review of Economic Studies, 29: 155-173.

Barge-Gil, A. (2010): "Cooperation-based innovators and peripheral cooperators: An empirical analysis of their characteristics and behaviour", Technovation, 30 (3): 195-206.

Belderbos, R., Carree, M., Lokshin, B. and Fernández Sastre, J. (2014): "Inter-temporal patterns of R\&D collaboration and innovative performance", The Journal of Tecbnology Transfer, 40(1): 123137.

Blanchard, P., Huiban, J.P., Musolesi, A. and Sevestre, P. (2012): "Where there is a will, there is a way? Assessing the impact of obstacles to innovation", Industrial and Corporate Change, 1: 1-32.

Bougheas, S., Görg, H. and Strobl, E. (2003): "Is R\&D financially constrained? Theory and evidence from Irish manufacturing". Review of Industrial Organization, 22(2): 159-174

Busom, I., Corchuelo, B. and Martínez Ros, E. (2014): "Tax incentives or subsidies for business R\&D?", Small Business Economics, 43(3): 571-598.

Canepa, A. and Stoneman, P. (2008): "Financial constraints to innovation in the UK: evidence from CIS2 and CIS3", Oxford Economic Papers, 60: 711-730.

Carreira, C. and Silva, F. (2010): “No deep pockets: some stylized empirical results on firms' financial constraints", Journal of Economic Surveys, 24(4): 731-753.

Chiao, C. (2002): "Relationship between debt, R\&D and physical investment, evidence from US firmlevel data", Applied Financial Economics, 12(2): 105-121.

Coad, A., Pellegrino, G. and Savona, M. (2016): "Barriers to innovation and firm productivity", Economics of Innovation and New Technology, 25(3): 321-334.

Czarnitzki, D. and Hottenrott, H. (2009): "R\&D Investment and Financing Constraints of Small and Medium-Sized Firms", Small Business Economics, 36: 65-83.

Czarnitzki, D. and Hottenrott, H. (2010): "Financing constraints for industrial innovation: what do we know?", Review of Busisness and Economic Literature, 55(3): 346-362.

D’Este, P., Amara, N. and Olmos, J. (2016): "Fostering novelty while reducing failure: Balancing the twin challenges of product innovation", Technological Forecasting \& Social Change, 113: 280-292.

D’Este, P., Iammarino, S., Savona, M., and von Tunzelmann, N. (2012): "What hampers innovation? Revealed barriers versus deterring barriers”, Research Policy, 41 (2): 482-488.

Efthyvoulou, G. and Vahter, P. (2016): "Financial constraints, innovation performance and sectoral disaggregation", The Manchester School, 84(2): 125-158.

Fazzari, S.M., Hubbard, R.G. and Petersen, B.C. (1988): "Financing Constraints and Corporate Investment", Brookings Papers on Economic Activity, 1: 141-195.

Galia, F., Mancini, S. and Morandi, V. (2012): “Obstacles to innovation: what hampers innovation in France and Italy?”, Paper presented to DRUID Society 2012.

García-Quevedo, J.; Pellegrino, G.; Savona, M.(2016): "Reviving demand-pull perspectives: The effect of demand uncertainty and stagnancy on R\&D strategy", Cambridge Journal of Economics, Advance Access, 1-31, doi:10.1093/cje/bew042.016.

Garcia-Vega, M. and Lopez, A. (2010): "Determinants of Abandoning Innovative Activities: Evidence from Spanish Firms", Cuadernos de Economia y Dirección de la Empresa, 13: 69-91.

Greene, W. H. (2003): Econometric analysis 5 th edition. New Jersey: Prentice Hall.

Hadlock, C.J. and Pierce, J.R. (2010): "New Evidence on Measuring Financial Constraints: Moving Beyond the KZ Index", The Review of Financial Studies, 23(5): 1909-1940. 
Hall, B.H. (1992): Investment and research and development at the firm level: does the source of financing matter? NBER Working Paper 4096, National Bureau of Economic Research.

Hall, B. H. (2002): "The financing of research and development", Oxford Review of Economic Policy, 18(1): 37-51.

Hall, B.H. and Lerner, J. (2010): "Financing R\&D and innovation", in B. H. Hall and N. Rosenberg (eds.), Handbook of the Economics of Innovation, pp. 609-639.

Harhoff, D. (1998): "Are there financing constraints for R\&D and investment in German manufacturing firms?", Annals of Economics and Statistics, 49/50: 421-456.

Himmelberg, C. P. and Petersen, B. C. (1994): "R\&D and internal finance: A panel study of small firms in high-tech industries", Review of Economics and Statistics, 76(1): 38-51.

Hoegla, M., Gibbert, M. and Mazursky, D. (2008): 'Financial constraints in innovation projects: When is less more?', Research Policy, 37 (8): 1382-1391

Hölzl, W. and Janger, J. (2014): "Distance to the frontier and the perception of innovation barriers across European countries", Research Policy, 43(4): 707-725.

Hottenrott, H. and Peters, B. (2012): "Innovative capability and financing constraints for innovation: more money, more innovation?”, The Review of Economics and Statistics, 94(4): 1126-1142.

Jain, B. A. and Kini, O. (2000): "Does the Presence of Venture Capitalists Improve the Survival Profile of IPO Firms?", Joumal of Business Finance and Accounting, 27(9): 1139-1176.

Kamien, M. and Schwartz, N. (1978): "Enterprise's Self-Financing of an R\&D project", Journal American Economic Review, 68: 252-261

Kaplan, S. N. and Zingales, L. (1997): "Do Investment-Cash Flow Sensitivities Provide Useful Measures of Financial Constraints?”, Quarterly Journal of Economics, 112:159-216.

Kerr, W., and Nanda, R. (2015): "Financing innovation", Bank of Finland Research. Discussion Papers $28 \cdot 2015$.

Landry, R., Amara, N. and Becheikh, N. (2008): Exploring innovation failures in manufacturing industries, Paper presented to DRUID Society 2008.

Lhuillery, S. and Pfister, E. (2009): "R\&D cooperation and failures in innovation projects: Empirical evidence from French CIS data", Research Policy, 38(1): 45-57.

Love, P.E.D.; Irani, Z.; Standing, C.; Lin, C. and Bum, J.M. (2005): "The enigma of evaluation: benefits, costs and risks of IT in Australian small-medium-sized enterprises", Information \& Management, 42: 947-964.

Mancusi, M. L. and Vezzulli, A. (2014): "R\&D and credit rationing in SMEs," Economic Inquiry, 52 (3): 1153-1172.

Mazzucato, M. (2013): “Financing innovation: creative destruction vs. destructive creation", Industrial and Corporate Change 22: 851-867.

Mina, A., Lahr, H. and Hughes, A. (2013): “The demand and supply of external finance for innovative firms", Industrial and Corporate Change 22: 869-901

Mohnen, P., Palm, F., van der Loeff, S. and Tiwari, A. (2008): "Financial Constraints and Other Obstacles: are they a Threat to Innovation Activity?”, De Economist, 156: 201-214.

Mulkay, B., Hall, B. and Mairesse, J. (2001): Firm level investment and R\&D in France and the United States: A comparison, NBER Working Paper 8038.

Myers, S.C. and Majluf, N.S. (1984) Corporate Financing and Investment Decision When Firms Have Information That Investors Do Not Have. Journal of Financial Economics, 13, 187-221.

Nelson, R..R. and Winter, S. (1982): An evolutionary theory of economic change, Harvard University Press, Cambridge. 
Rabe-Hesketh, S. and Skrondal, A (2013): “Avoiding biased versions of Wooldridge's simple solution to the initial conditions problem", Economics Letters, 120: 346-349.

Salies, E. (2010): "A test of the Schumpeterian hypothesis in a panel of European electric utilities". In: Gaffard, J.L., Salies, E. (Eds.), Innovation, Economic Growth and the Firm. Edward Elgar Publishing.

Savignac, F. (2008): "Impact of Financial Constraints on Innovation: What Can Be Learned from a Direct Measure?", Economics of Innovation and New Technology, 17(6): 553-69.

Schneider, C. and Veugelers, R. (2010): "On young highly innovative companies: why they matter and how (not) to policy to support them", Industrial and Corporate Change, 19 (4): 969-1007.

Segarra, A., Garcia, J. and Teruel, M. (2008): "Barriers to innovation and public policy in Catalonia", International Entrepreneurship and Management Journal, 4(4): 431-451.

Tiwari, A.K., Mohnen, P., Palm, F.C. and van der Loeff, S.S. (2008): "Financial Constraints and R\&D Investment: Evidence from CIS, in A. Kleinknecht, R. Ott, C. van Beers and R. Verburg (eds.), Determinants of Innovative Behaviour: A Firm's Internal Practices and its External Environments. Palgrave Macmillan: London, pp. 217-242.

Whited, T. and Wu, G. (2006): "Financial Constraints Risk", Review of Financial Studies, 19:531-59.

Wooldridge, J.M. (2005): "Simple solutions to the initial conditions problem in dynamic, nonlinear panel data models with unobserved heterogeneity", Journal of Applied Econometrics, 20 (1): 39-54. 


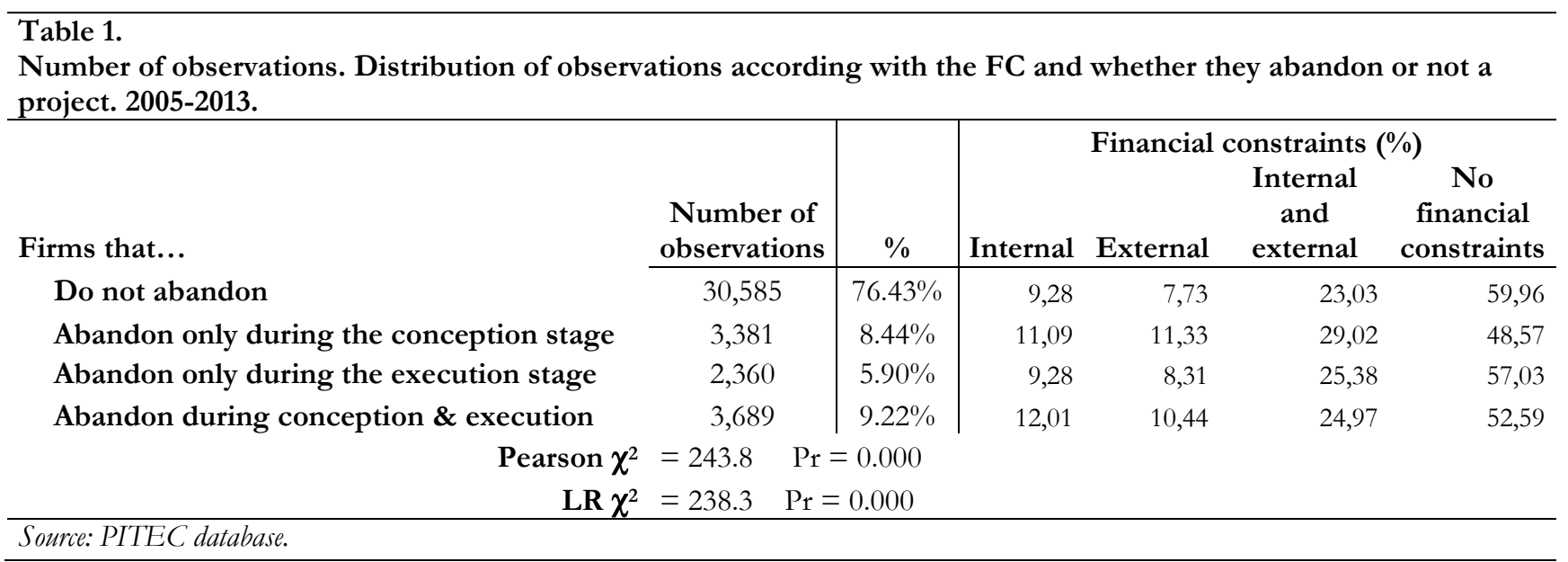




\begin{tabular}{|c|c|c|c|c|c|}
\hline \multicolumn{6}{|c|}{$\begin{array}{l}\text { Table } 2 . \\
\text { Statistical descriptive. Mean and Standard deviations between brackets. 2005-2013 } \\
\text { (A) Firms that abandon a proiect }\end{array}$} \\
\hline & $\begin{array}{l}\text { Firms that } \\
\text { do not } \\
\text { abandon a } \\
\text { project }\end{array}$ & $\begin{array}{l}\text { (B) } \\
\text { during any } \\
\text { stage }\end{array}$ & $\begin{array}{l}\text { (C) } \\
\text { during the } \\
\text { conception } \\
\text { phase }\end{array}$ & $\begin{array}{l}\text { (D) } \\
\text { during the } \\
\text { execution } \\
\text { stage }\end{array}$ & $\begin{array}{c}\text { Wilks' } \\
\text { lambda F } \\
\text { (Prob>F) } \\
\text { (A) vs. (B) }\end{array}$ \\
\hline AB_conc_proj & - & $\begin{array}{c}1.00 \\
(0.00)\end{array}$ & $\begin{array}{c}1.00 \\
(0.00)\end{array}$ & $\begin{array}{c}1.00 \\
(0.00)\end{array}$ & - \\
\hline AB_concept & - & $\begin{array}{c}0.75 \\
(0.43)\end{array}$ & $\begin{array}{c}1.00 \\
(0.00)\end{array}$ & $\begin{array}{c}0.61 \\
(0.49)\end{array}$ & $\begin{array}{c}91620.82 \\
(0.000)\end{array}$ \\
\hline AB_project & - & $\begin{array}{c}0.64 \\
(0.48)\end{array}$ & $\begin{array}{c}0.52 \\
(0.50)\end{array}$ & $\begin{array}{c}1.00 \\
(0.00)\end{array}$ & $\begin{array}{c}54717.37 \\
(0.000)\end{array}$ \\
\hline FC & $\begin{array}{c}0.40 \\
(0.49)\end{array}$ & $\begin{array}{c}0.48 \\
(0.50)\end{array}$ & $\begin{array}{c}0.49 \\
(0.50)\end{array}$ & $\begin{array}{c}0.46 \\
(0.50)\end{array}$ & $\begin{array}{l}176.30 \\
(0.000)\end{array}$ \\
\hline FC_internal & $\begin{array}{c}0.32 \\
(0.47)\end{array}$ & $\begin{array}{c}0.38 \\
(0.48)\end{array}$ & $\begin{array}{c}0.38 \\
(0.49)\end{array}$ & $\begin{array}{c}0.36 \\
(0.48)\end{array}$ & $\begin{array}{c}87.92 \\
(0.000)\end{array}$ \\
\hline FC_external & $\begin{array}{c}0.31 \\
(0.46)\end{array}$ & $\begin{array}{c}0.37 \\
(0.48)\end{array}$ & $\begin{array}{c}0.38 \\
(0.48)\end{array}$ & $\begin{array}{c}0.35 \\
(0.48)\end{array}$ & $\begin{array}{l}118.63 \\
(0.000)\end{array}$ \\
\hline Age & $\begin{array}{c}27.12 \\
(19.51)\end{array}$ & $\begin{array}{c}28.36 \\
(20.03)\end{array}$ & $\begin{array}{c}28.74 \\
(20.19)\end{array}$ & $\begin{array}{c}28.83 \\
(20.31)\end{array}$ & $\begin{array}{c}28.70 \\
(0.000)\end{array}$ \\
\hline Size & $\begin{array}{c}161.28 \\
(534.54)\end{array}$ & $\begin{array}{c}228.91 \\
(985.31)\end{array}$ & $\begin{array}{c}261.71 \\
(1,123.20)\end{array}$ & $\begin{array}{c}223.78 \\
(935.92)\end{array}$ & $\begin{array}{c}73.73 \\
(0.000)\end{array}$ \\
\hline $\mathrm{RD}$ & $\begin{array}{c}0.66 \\
(0.47)\end{array}$ & $\begin{array}{c}0.83 \\
(0.37)\end{array}$ & $\begin{array}{c}0.92 \\
(0.27)\end{array}$ & $\begin{array}{c}0.81 \\
(0.39)\end{array}$ & $\begin{array}{c}1061.42 \\
(0.000)\end{array}$ \\
\hline Group & $\begin{array}{c}0.34 \\
(0.47)\end{array}$ & $\begin{array}{c}0.42 \\
(0.49)\end{array}$ & $\begin{array}{c}0.44 \\
(0.50)\end{array}$ & $\begin{array}{c}0.43 \\
(0.49)\end{array}$ & $\begin{array}{l}210.89 \\
(0.000)\end{array}$ \\
\hline Know & $\begin{array}{c}0.82 \\
(0.39)\end{array}$ & $\begin{array}{c}0.92 \\
(0.27)\end{array}$ & $\begin{array}{c}0.94 \\
(0.23)\end{array}$ & $\begin{array}{c}0.91 \\
(0.28)\end{array}$ & $\begin{array}{l}598.65 \\
(0.000)\end{array}$ \\
\hline Market & $\begin{array}{c}0.82 \\
(0.39)\end{array}$ & $\begin{array}{c}0.92 \\
(0.27)\end{array}$ & $\begin{array}{c}0.94 \\
(0.23)\end{array}$ & $\begin{array}{c}0.91 \\
(0.28)\end{array}$ & $\begin{array}{l}590.10 \\
(0.000)\end{array}$ \\
\hline Coop & $\begin{array}{c}0.28 \\
(0.45)\end{array}$ & $\begin{array}{c}0.45 \\
(0.50)\end{array}$ & $\begin{array}{c}0.49 \\
(0.50)\end{array}$ & $\begin{array}{c}0.44 \\
(0.50)\end{array}$ & $\begin{array}{l}974.50 \\
(0.000)\end{array}$ \\
\hline InternatMarket & $\begin{array}{c}0.71 \\
(0.45)\end{array}$ & $\begin{array}{c}0.83 \\
(0.38)\end{array}$ & $\begin{array}{c}0.85 \\
(0.36)\end{array}$ & $\begin{array}{c}0.83 \\
(0.37)\end{array}$ & $\begin{array}{l}510.38 \\
(0.000)\end{array}$ \\
\hline RDintensity & $\begin{array}{c}7,196.94 \\
(30,359.48)\end{array}$ & $\begin{array}{c}10,805.42 \\
(49,940.24)\end{array}$ & $\begin{array}{c}12,007.25 \\
(55,728.57)\end{array}$ & $\begin{array}{c}11,189.39 \\
(60,638.87)\end{array}$ & $\begin{array}{c}72.63 \\
(0.000))\end{array}$ \\
\hline KLsect & $\begin{array}{c}11.73 \\
(37.95)\end{array}$ & $\begin{array}{c}10.33 \\
(26.30)\end{array}$ & $\begin{array}{c}10.05 \\
(23.08)\end{array}$ & $\begin{array}{c}10.57 \\
(27.96)\end{array}$ & $\begin{array}{l}11.15 \\
(0.000)\end{array}$ \\
\hline FinLocReg & $\begin{array}{c}0.21 \\
(0.41)\end{array}$ & $\begin{array}{c}0.28 \\
(0.45)\end{array}$ & $\begin{array}{c}0.30 \\
(0.46)\end{array}$ & $\begin{array}{c}0.26 \\
(0.44)\end{array}$ & $\begin{array}{l}186.62 \\
(0.000)\end{array}$ \\
\hline FinState & $\begin{array}{c}0.20 \\
(0.40)\end{array}$ & $\begin{array}{c}0.29 \\
(0.45)\end{array}$ & $\begin{array}{c}0.32 \\
(0.47)\end{array}$ & $\begin{array}{c}0.27 \\
(0.45)\end{array}$ & $\begin{array}{l}372.17 \\
(0.000)\end{array}$ \\
\hline FinEur & $\begin{array}{c}0.04 \\
(0.20)\end{array}$ & $\begin{array}{c}0.08 \\
(0.26)\end{array}$ & $\begin{array}{c}0.09 \\
(0.28)\end{array}$ & $\begin{array}{c}0.07 \\
(0.25)\end{array}$ & $\begin{array}{l}192.76 \\
(0.000)\end{array}$ \\
\hline Patents $(+1)$ & $\begin{array}{c}1.44 \\
(6.17)\end{array}$ & $\begin{array}{c}2.18 \\
(8.29)\end{array}$ & $\begin{array}{c}2.40 \\
(9.46)\end{array}$ & $\begin{array}{c}2.29 \\
(9.78)\end{array}$ & $\begin{array}{c}87.71 \\
(0.000)\end{array}$ \\
\hline Observations & 30,585 & 9,430 & 7,070 & 6,049 & \\
\hline
\end{tabular}




\section{Table 3.}

Spearman's rank correlation.

\begin{tabular}{|c|c|c|c|c|c|c|c|c|c|c|c|c|c|c|c|c|c|c|c|c|}
\hline & (1) & (2) & (3) & (4) & (5) & (6) & (7) & $(8)$ & (9) & (10) & (11) & $(12)$ & (13) & (14) & (15) & (16) & (17) & (18) & (19) & (20) \\
\hline (1) AB_conc_proj & 1.000 & & & & & & & & & & & & & & & & & & & \\
\hline (2) AB_concept & $0.834 *$ & 1.000 & & & & & & & & & & & & & & & & & & \\
\hline (3) AB_project & $0.760 *$ & $0.479 *$ & 1.000 & & & & & & & & & & & & & & & & & \\
\hline (4) FC & $0.066^{*}$ & $0.070^{*}$ & $0.033^{*}$ & 1.000 & & & & & & & & & & & & & & & & \\
\hline (5) FC_internal & $0.047^{*}$ & $0.048^{*}$ & $0.023^{*}$ & $0.837^{*}$ & 1.000 & & & & & & & & & & & & & & & \\
\hline (6) FC_external & $0.054 *$ & $0.055^{*}$ & $0.023^{*}$ & $0.812^{*}$ & $0.592 *$ & 1.000 & & & & & & & & & & & & & & \\
\hline (7) Age & $0.027^{*}$ & $0.031 *$ & $0.031 *$ & $-0.090 *$ & $-0.086^{*}$ & $-0.076^{*}$ & 1.000 & & & & & & & & & & & & & \\
\hline (8) Size & $0.043^{*}$ & $0.058^{*}$ & $0.029 *$ & $-0.068 *$ & $-0.062 *$ & $-0.072 *$ & $0.201 *$ & 1.000 & & & & & & & & & & & & \\
\hline (9) $\mathrm{RD}$ & $0.161 *$ & $0.222^{*}$ & $0.098^{*}$ & $0.022^{*}$ & $-0.016^{*}$ & $0.025^{*}$ & $0.018^{*}$ & $0.064 *$ & 1.000 & & & & & & & & & & & \\
\hline (10) Group & $0.072 *$ & $0.080^{*}$ & $0.057^{*}$ & $-0.138^{*}$ & $-0.143 *$ & $-0.126^{*}$ & $0.123^{*}$ & $0.196^{*}$ & $0.127^{*}$ & 1.000 & & & & & & & & & & \\
\hline (11) KLsector & $-0.017 *$ & $-0.018^{*}$ & $-0.010^{*}$ & $-0.036^{*}$ & $-0.030^{*}$ & $-0.029 *$ & $-0.016^{*}$ & $0.001 *$ & -0.063 & $0.040^{*}$ & 1.000 & & & & & & & & & \\
\hline (12) Know & $0.121 *$ & $0.128^{*}$ & $0.082^{*}$ & $0.220^{*}$ & $0.183^{*}$ & $0.191 *$ & $-0.019 *$ & $-0.007 *$ & $0.228^{*}$ & $-0.020^{*}$ & $-0.064 *$ & 1.000 & & & & & & & & \\
\hline (13) Market & $0.121 *$ & $0.128^{*}$ & $0.080^{*}$ & $0.184^{*}$ & $0.157^{*}$ & $0.155^{*}$ & $-0.024 *$ & $-0.027 *$ & $0.201 *$ & $-0.019 *$ & $-0.063 *$ & $0.583^{*}$ & 1.000 & & & & & & & \\
\hline (14) Coop & $0.154 *$ & $0.170^{*}$ & $0.107^{*}$ & $0.023^{*}$ & 0.006 & $0.017^{*}$ & 0.021 & $0.094 *$ & $0.290^{*}$ & $0.173^{*}$ & $-0.003 *$ & $0.125^{*}$ & $0.101 *$ & 1.000 & & & & & & \\
\hline (15) InternatMarket & $0.112^{*}$ & $0.113^{*}$ & $0.088^{*}$ & -0.006 & $-0.028^{*}$ & 0.004 & $0.127^{*}$ & $0.017^{*}$ & $0.197 *$ & $0.129 *$ & -0.083 & $0.111 *$ & $0.124^{*}$ & $0.091 *$ & 1.000 & & & & & \\
\hline (16) RDintensity & $0.043^{*}$ & $0.051 *$ & $0.037^{*}$ & $0.017^{*}$ & $-0.006^{*}$ & $0.023^{*}$ & $-0.071 *$ & -0.004 & $0.146^{*}$ & $0.027^{*}$ & $0.004 *$ & $0.034 *$ & $0.030^{*}$ & $0.129 *$ & $0.006^{*}$ & 1.000 & & & & \\
\hline (17) FinLocReg & $0.068^{*}$ & $0.084 *$ & $0.031 *$ & $0.039 *$ & $0.029 *$ & $0.025^{*}$ & $-0.071 *$ & $0.004 *$ & $0.301 *$ & 0.016 & $-0.043 *$ & $0.121 *$ & $0.094 *$ & $0.291 *$ & $0.070^{*}$ & $0.138^{*}$ & 1.000 & & & \\
\hline (18) FinState & $0.096^{*}$ & $0.111 *$ & $0.054 *$ & $0.021 *$ & $0.012^{*}$ & $0.021 *$ & $-0.000^{*}$ & $0.081 *$ & $0.315^{*}$ & $0.124^{\wedge} *$ & $-0.026^{*}$ & $0.111 *$ & $0.099 *$ & $0.324 *$ & $0.109 *$ & $0.169^{*}$ & $0.314^{*}$ & 1.000 & & \\
\hline (19) FinEur & $0.069 *$ & $0.083^{*}$ & $0.033^{*}$ & $0.040^{*}$ & $0.031 *$ & $0.039 *$ & $-0.036^{*}$ & $0.027 *$ & $0.135^{*}$ & -0.001 & $-0.027 *$ & $0.056^{*}$ & $0.044 *$ & $0.212^{*}$ & $0.042^{*}$ & $0.174 *$ & $0.228^{*}$ & $0.280^{*}$ & 1.000 & \\
\hline (20) Patents & $0.047^{*}$ & $0.054^{*}$ & $0.043^{*}$ & -0.015 & $-0.019 *$ & $-0.009 *$ & $0.032^{*}$ & $0.076^{*}$ & $0.055^{*}$ & $0.052^{*}$ & -0.004 & $0.009 *$ & $0.009 *$ & $0.062^{*}$ & $0.041^{*}$ & $0.055^{*}$ & $0.051 *$ & $0.080^{*}$ & $0.055^{*}$ & 1.000 \\
\hline
\end{tabular}


Table 4.

Recursive bivariate probit of the probability of abandoning a project and perceiving financial constraints

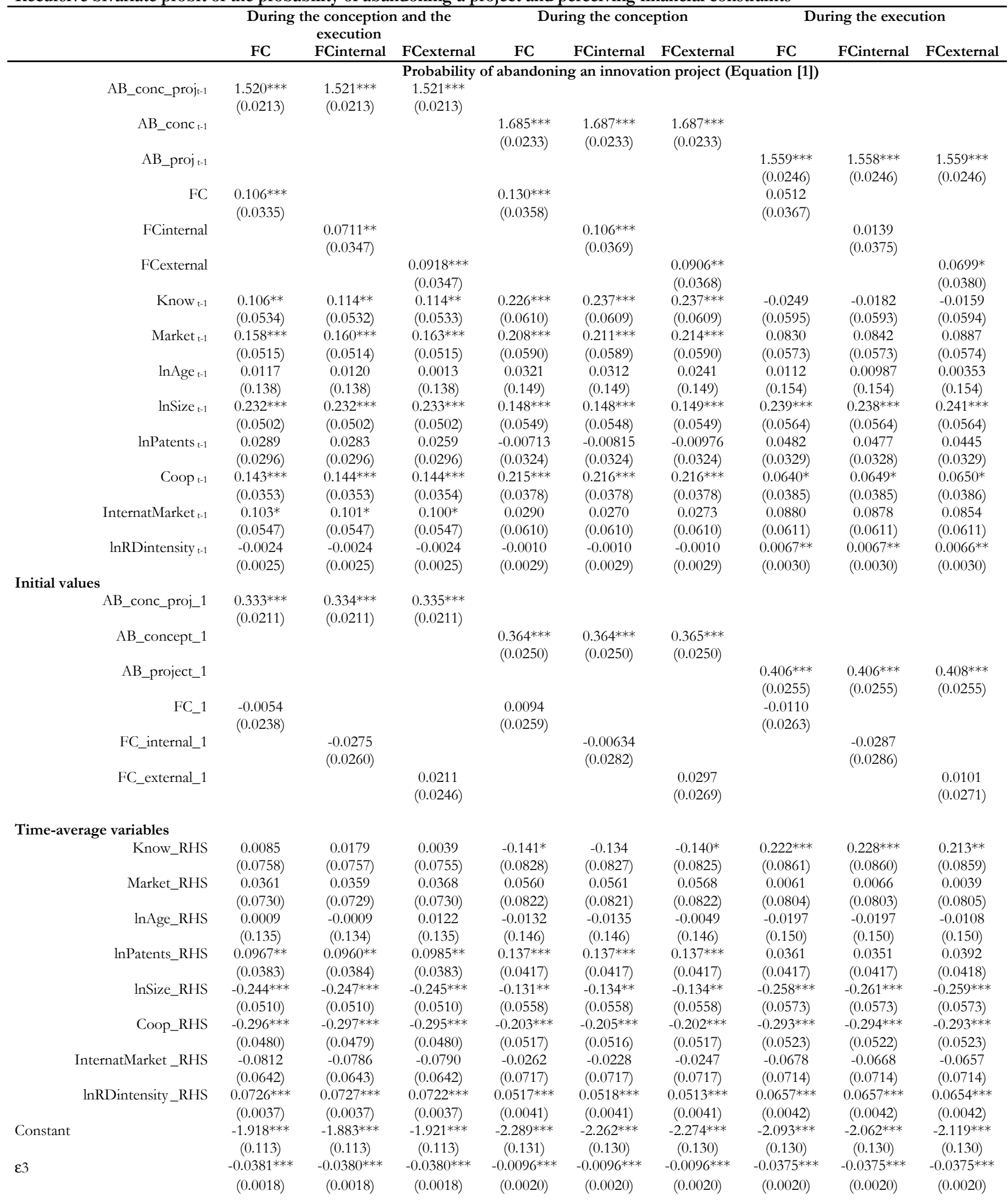

Probability of perceiving financial constraints (Equation [2])

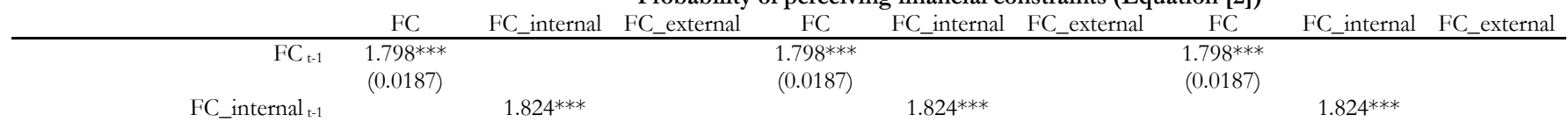




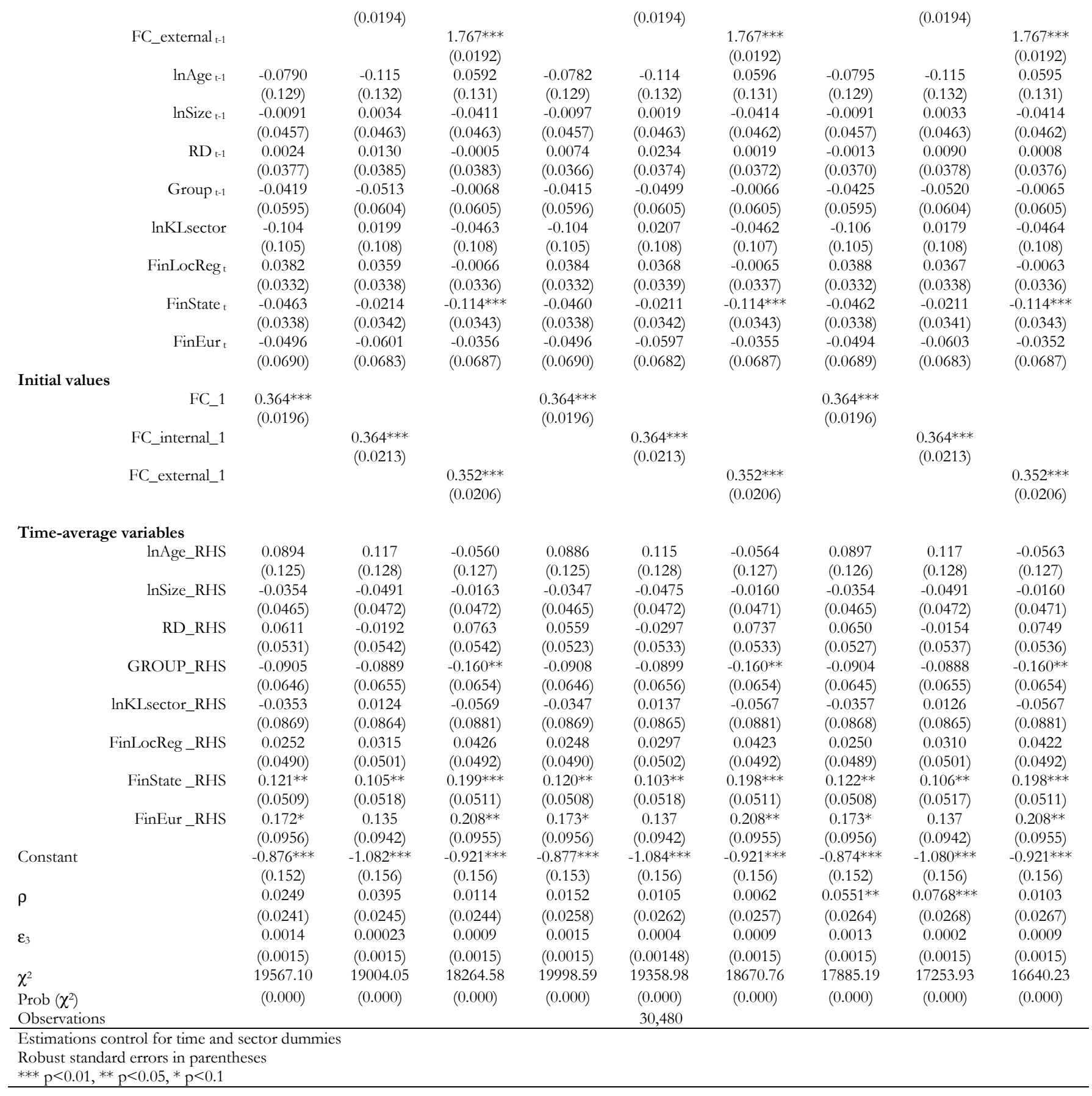


Table 5.

Marginal probability of the impact of perceiving financial constraints

\begin{tabular}{|c|c|c|c|}
\hline & \multicolumn{3}{|c|}{ During the conception and the execution } \\
\hline & \multirow[t]{2}{*}{ Probability } & \multicolumn{2}{|c|}{$\begin{array}{c}\text { H0: FCinternal=0 } \\
\text { or H0: } \text { FCexternal=0 }\end{array}$} \\
\hline & & $\chi^{2}$ & Prob $>\chi^{2}$ \\
\hline$P($ AB_conc_proj=1 $\mid$ FCinternal $=1)$ & $1.416 \%$ & 4.19 & 0.041 \\
\hline \multirow[t]{4}{*}{$P\left(A B \_c o n c \_p r o j=1 \mid F C e x t e r n a l=1\right)$} & $1.829 \%$ & 7.00 & 0.008 \\
\hline & \multicolumn{3}{|c|}{ During the conception } \\
\hline & \multirow[t]{2}{*}{ Probability } & \multicolumn{2}{|c|}{$\begin{array}{c}\text { H0: FCinternal=0 } \\
\text { or Ho: FCexternal=0 }\end{array}$} \\
\hline & & $\chi^{2}$ & Prob $>\chi^{2}$ \\
\hline$P\left(A B \_\right.$conc $=1 \mid F C$ internal $\left.=1\right)$ & $1.690 \%$ & 8.20 & 0.004 \\
\hline \multirow[t]{4}{*}{$P\left(A B \_\right.$conc $=1 \mid F C$ external $\left.=1\right)$} & $1.452 \%$ & 6.07 & 0.014 \\
\hline & \multicolumn{3}{|c|}{ During the execution } \\
\hline & \multirow[t]{2}{*}{ Probability } & \multicolumn{2}{|c|}{$\begin{array}{c}\text { H0: FCinternal=0 } \\
\text { or Ho: FCexternal=0 }\end{array}$} \\
\hline & & $\chi^{2}$ & Prob $>\chi^{2}$ \\
\hline$P\left(A B \_\right.$proj $=1 \mid F C$ internal $\left.=1\right)$ & $0.216 \%$ & 0.14 & 0.710 \\
\hline$P\left(A B \_\right.$proj $\left.=1 \mid F C e x t e r n a l=1\right)$ & $1.084 \%$ & 3.38 & 0.066 \\
\hline \multicolumn{4}{|c|}{ Source: own elaboration from PITEC database. } \\
\hline
\end{tabular}




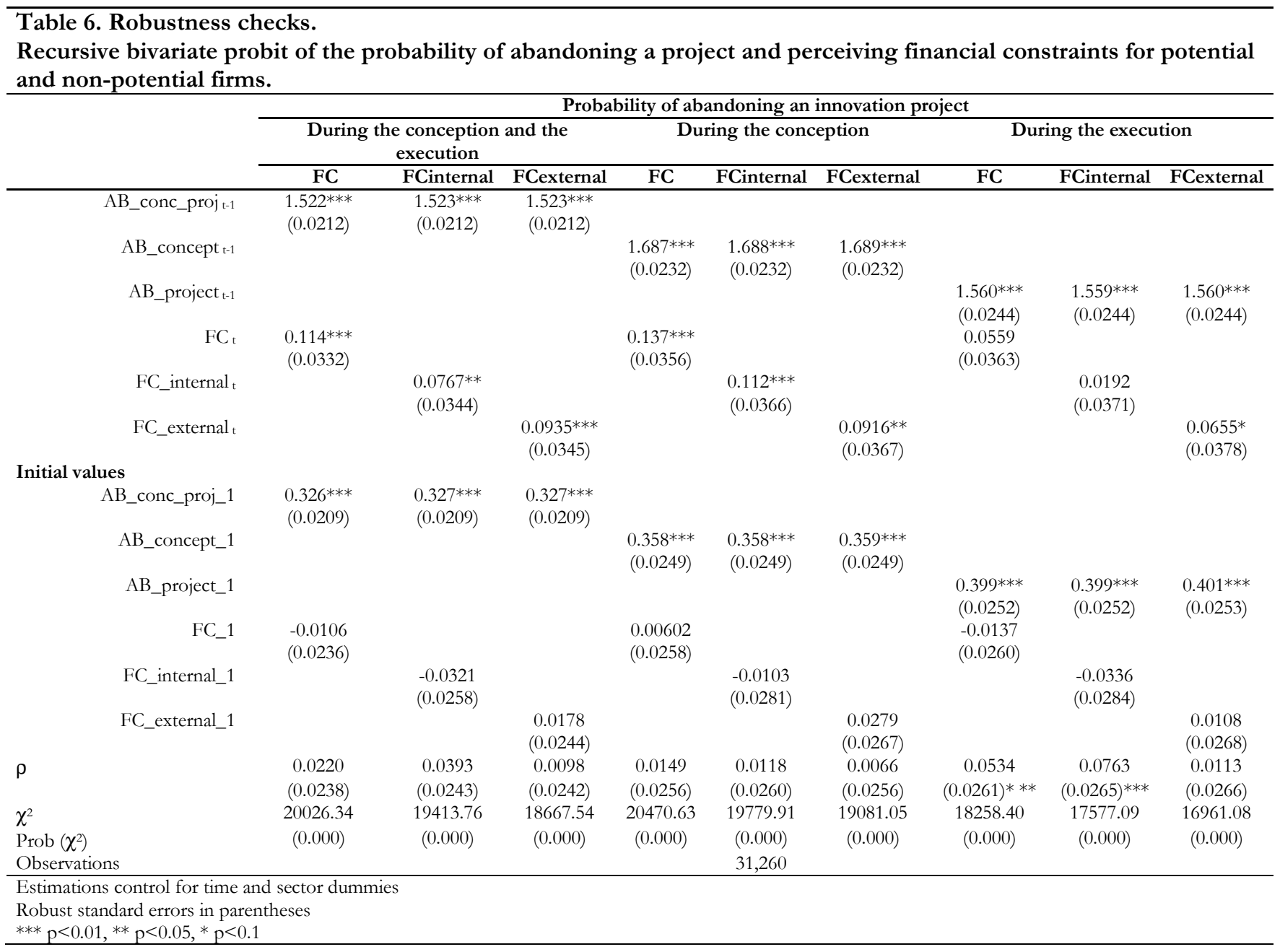


Table 7. Robustness checks.

Recursive bivariate probit of the probability of abandoning a project for the whole database.

\begin{tabular}{|c|c|c|c|c|c|c|c|c|c|c|}
\hline & & \multicolumn{9}{|c|}{ Probability of abandoning an innovation project } \\
\hline & & \multicolumn{3}{|c|}{$\begin{array}{c}\text { During the conception and the } \\
\text { execution }\end{array}$} & \multicolumn{3}{|c|}{ During the conception } & \multicolumn{3}{|c|}{ During the execution } \\
\hline & & FC & FCinternal & FCexternal & FC & FCinternal & FCexternal & FC & FCinternal & FCexternal \\
\hline & AB_conc_proj $\mathrm{t}-1$ & $\begin{array}{l}1.522^{* * *} \\
(0.0208)\end{array}$ & $\begin{array}{l}1.522^{* * *} \\
(0.0208)\end{array}$ & $\begin{array}{l}1.522^{* * *} \\
(0.0208)\end{array}$ & & & & & & \\
\hline & AB_concept $\mathrm{t}-1$ & & & & $\begin{array}{l}1.685^{* * *} \\
(0.0227)\end{array}$ & $\begin{array}{l}1.686 * * * \\
(0.0227)\end{array}$ & $\begin{array}{l}1.686^{* * *} \\
(0.0227)\end{array}$ & & & \\
\hline & AB_project $t-1$ & & & & & & & $\begin{array}{l}1.561 * * * \\
(0.0240)\end{array}$ & $\begin{array}{l}1.560 * * * \\
(0.0240)\end{array}$ & $\begin{array}{l}1.561 * * * \\
(0.0240)\end{array}$ \\
\hline & $\mathrm{FC}_{\mathrm{t}}$ & $\begin{array}{l}0.108 * * * \\
(0.0325)\end{array}$ & & & $\begin{array}{c}0.131 * * * \\
(0.0348)\end{array}$ & & & $\begin{array}{c}0.0574 \\
(0.0356)\end{array}$ & & \\
\hline & $\mathrm{FC}_{\text {_internal }} \mathrm{t}$ & & $\begin{array}{c}0.0710^{* *} \\
(0.0337)\end{array}$ & & & $\begin{array}{c}0.0992 * * * \\
(0.0359)\end{array}$ & & & $\begin{array}{c}0.0209 \\
(0.0364)\end{array}$ & \\
\hline & FC_external ${ }_{t}$ & & & $\begin{array}{c}0.0930^{* * *} \\
(0.0336)\end{array}$ & & & $\begin{array}{c}0.0948^{* * *} \\
(0.0358)\end{array}$ & & & $\begin{array}{c}0.0714^{*} \\
(0.0368)\end{array}$ \\
\hline \multicolumn{11}{|l|}{ Initial values } \\
\hline & AB_conc_proj_1 & $\begin{array}{l}0.326^{* * *} \\
(0.0206)\end{array}$ & $\begin{array}{c}0.327^{* * *} \\
(0.0206)\end{array}$ & $\begin{array}{c}0.327^{* * *} \\
(0.0206)\end{array}$ & & & & & & \\
\hline & AB_concept_1 & & & & $\begin{array}{c}0.360 * * * \\
(0.0244)\end{array}$ & $\begin{array}{l}0.359 * * * \\
(0.0244)\end{array}$ & $\begin{array}{c}0.360 * * * \\
(0.0244)\end{array}$ & & & \\
\hline & AB_project_1 & & & & & & & $\begin{array}{r}0.396^{* * *} \\
(0.0248)\end{array}$ & $\begin{array}{r}0.396 * * * \\
(0.0248)\end{array}$ & $\begin{array}{c}0.398 * * * \\
(0.0248)\end{array}$ \\
\hline & FC_1 & $\begin{array}{l}-0.00677 \\
(0.0231)\end{array}$ & & & $\begin{array}{l}0.00786 \\
(0.0252)\end{array}$ & & & $\begin{array}{l}-0.0119 \\
(0.0255)\end{array}$ & & \\
\hline & FC_internal_1 & & $\begin{array}{l}-0.0288 \\
(0.0252)\end{array}$ & & & $\begin{array}{r}-0.00490 \\
(0.0274)\end{array}$ & & & $\begin{array}{l}-0.0344 \\
(0.0277)\end{array}$ & \\
\hline & FC_external_1 & & & $\begin{array}{c}0.0200 \\
(0.0239)\end{array}$ & & & $\begin{array}{c}0.0248 \\
(0.0261)\end{array}$ & & & $\begin{array}{c}0.0139 \\
(0.0262)\end{array}$ \\
\hline$\rho$ & & 0.0308 & $0.0461 *$ & 0.00593 & 0.0235 & 0.0236 & 0.00387 & $0.0561 * *$ & $0.0770^{* * *}$ & 0.00364 \\
\hline & & $(0.0234)$ & $(0.0238)$ & $(0.0237)$ & $(0.0251)$ & $(0.0255)$ & $(0.0250)$ & $(0.0256)$ & $(0.0259)$ & $(0.0259)$ \\
\hline$\chi^{2}$ & & 20895.00 & 20299.94 & 19449.52 & 21374.39 & 20692.27 & 19934.66 & 19067.89 & 18381.13 & 17650.06 \\
\hline $\operatorname{Prob}\left(\chi^{2}\right)$ & & $(0.000)$ & $(0.000)$ & $(0.000)$ & $(0.000)$ & $(0.000)$ & $(0.000)$ & $(0.000)$ & $(0.000)$ & $(0.000)$ \\
\hline Observations & & & & & & 32,658 & & & & \\
\hline $\begin{array}{l}\text { Estimations } \mathrm{co} \\
\text { Robust standa } \\
* * * \mathrm{p}<0.01, * *\end{array}$ & $\begin{array}{l}\text { for time and sect } \\
\text { ors in parentheses } \\
.05,{ }^{*} \mathrm{p}<0.1\end{array}$ & or dummies & & & & & & & & \\
\hline
\end{tabular}


Table 8. Robustness checks.

Recursive bivariate probit of the probability of abandoning a project for firms perceiving a medium or high intensity of financial constraints.

\begin{tabular}{|c|c|c|c|c|c|c|c|c|c|c|}
\hline & & \multicolumn{9}{|c|}{ Probability of abandoning an innovation project } \\
\hline & & \multicolumn{3}{|c|}{$\begin{array}{c}\text { During the conception and the } \\
\text { execution }\end{array}$} & \multicolumn{3}{|c|}{ During the conception } & \multicolumn{3}{|c|}{ During the execution } \\
\hline & & FC & FCinternal & FCexternal & FC & FCinternal & FCexternal & FC & FCinternal & FCexternal \\
\hline & AB_conc_proj t-1 & $\begin{array}{l}1.522^{* * *} \\
(0.0213)\end{array}$ & $\begin{array}{l}1.521 * * * \\
(0.0213)\end{array}$ & $\begin{array}{l}1.523 * * * \\
(0.0213)\end{array}$ & & & & & & \\
\hline & AB_concept $t_{\mathrm{t}-1}$ & & & & $\begin{array}{l}1.688^{* * *} \\
(0.0233)\end{array}$ & $\begin{array}{l}1.687 * * * \\
(0.0233)\end{array}$ & $\begin{array}{l}1.690 * * * \\
(0.0233)\end{array}$ & & & \\
\hline & AB_project $t-1$ & & & & & & & $\begin{array}{l}1.560^{* * *} \\
(0.0246)\end{array}$ & $\begin{array}{l}1.560 * * * \\
(0.0246)\end{array}$ & $\begin{array}{l}1.561 * * * \\
(0.0246)\end{array}$ \\
\hline & $\mathrm{FC}_{\mathrm{t}}$ & $\begin{array}{c}0.108^{* * *} \\
(0.0394)\end{array}$ & & & $\begin{array}{l}0.109 * * \\
(0.0432)\end{array}$ & & & $\begin{array}{c}0.0617 \\
(0.0426)\end{array}$ & & \\
\hline & FC_internal $t$ & & $\begin{array}{c}0.111^{* * *} \\
(0.0366)\end{array}$ & & & $\begin{array}{c}0.114^{* * *} \\
(0.0397)\end{array}$ & & & $\begin{array}{c}0.0551 \\
(0.0397)\end{array}$ & \\
\hline & FC_external $t$ & & & $\begin{array}{l}0.0610^{*} \\
(0.0356)\end{array}$ & & & $\begin{array}{l}0.0710^{*} \\
(0.0385)\end{array}$ & & & $\begin{array}{c}0.0213 \\
(0.0387)\end{array}$ \\
\hline \multicolumn{11}{|l|}{ Initial values } \\
\hline & AB_conc_proj_1 & $\begin{array}{c}0.336^{* * *} \\
(0.0211)\end{array}$ & $\begin{array}{c}0.336^{* * *} \\
(0.0211)\end{array}$ & $\begin{array}{c}0.336^{* * *} \\
(0.0211)\end{array}$ & & & & & & \\
\hline & AB_concept_1 & & & & $\begin{array}{c}0.369 * * * \\
(0.0250)\end{array}$ & $\begin{array}{c}0.367 * * * \\
(0.0250)\end{array}$ & $\begin{array}{c}0.369 * * * \\
(0.0250)\end{array}$ & & & \\
\hline & AB_project_1 & & & & & & & $\begin{array}{l}0.406 * * * \\
(0.0255)\end{array}$ & $\begin{array}{c}0.407 * * * \\
(0.0255)\end{array}$ & $\begin{array}{c}0.407 * * * \\
(0.0255)\end{array}$ \\
\hline & FC_1 & $\begin{array}{l}-0.0067 \\
(0.0245)\end{array}$ & & & $\begin{array}{l}-0.0063 \\
(0.0270)\end{array}$ & & & $\begin{array}{l}-0.0034 \\
(0.0269)\end{array}$ & & \\
\hline & FC_internal_1 & & $\begin{array}{l}-0.0168 \\
(0.0236)\end{array}$ & & & $\begin{array}{l}0.00125 \\
(0.0259)\end{array}$ & & & $\begin{array}{l}-0.0038 \\
(0.0260)\end{array}$ & \\
\hline & FC_external_1 & & & $\begin{array}{c}0.0132 \\
(0.0230)\end{array}$ & & & $\begin{array}{r}-0.00175 \\
(0.0251)\end{array}$ & & & $\begin{array}{c}0.0175 \\
(0.0254)\end{array}$ \\
\hline$\rho$ & & 0.0240 & 0.0166 & 0.0255 & $0.0616^{* *}$ & 0.0334 & 0.0352 & 0.0065 & $\begin{array}{c}0.0159 \\
0\end{array}$ & 0.0061 \\
\hline$\chi^{2}$ & & 18663.20 & 19564.38 & 19116.08 & 19135.62 & 20037.34 & 19591.70 & 16892.75 & 17745.46 & 17507.73 \\
\hline $\operatorname{Prob}\left(\chi^{2}\right)$ & & $(0.000)$ & $(0.000)$ & $(0.000)$ & $(0.000)$ & $(0.000)$ & $(0.000)$ & $(0.000)$ & $(0.000)$ & $(0.000)$ \\
\hline Observations & & & & & & 30,480 & & & & \\
\hline $\begin{array}{l}\text { Estimations co } \\
\text { Robust standar } \\
* * * \mathrm{p}<0.01 \text {, ** }\end{array}$ & $\begin{array}{l}\text { time and sector } \\
\text { in parentheses } \\
* \mathrm{p}<0.1\end{array}$ & ammies & & & & & & & & \\
\hline
\end{tabular}

